\title{
Overview of the Legal Aspects and Contract Requirements of the BIM Practice in Malaysian Construction Industry
}

\author{
Teoh Ming Jo ${ }^{1, *}$, Siti Salwa Mohd Ishak ${ }^{1}$, and Zul Zakiyuddin Ahmad Rashid ${ }^{1}$ \\ ${ }^{1}$ School of Housing, Building and Planning, Universiti Sains Malaysia (USM), 11800 USM, Penang, \\ Malaysia
}

\begin{abstract}
Legal, contractual issues and the absence of appropriate protocols have been ranked as critical barriers associated with the implementation of Building Information Modelling (BIM). As to date, these issues are under studied and there is lack of framework addressing legal and contractual measures ensuring contract best practice in BIM project setting and legal environment in Malaysia. This research attempts to review legal issues and two common local standard forms of contract in order to highlight provisions to suit BIM practice. The potential legal issues that were drawn from literature review are ownership of BIM model, intellectual property rights, level of development of the model, model management, allocation of risk, and schedule of deliverables. Appropriate adjustment or inclusion of the clauses or the contract contents is proposed, it could then be made to fit BIM practice.
\end{abstract}

\section{Introduction}

In the current era of digitization construction, Building Information Modelling (BIM) technology that has been commonly used in Malaysia such as Autodesk Revit, Tekla, and Glodon, has become rudiments in the construction industry. BIM technology has been promoted as a highly effective as well as productive method which can reduce the construction cost, time, and risk from designing to construction stage of the project. It provides a design environment that can integrate all design disciplines and project teams involved in a building project. Architects usually perceived BIM as an easy route to deliver 3D design, while contractors focus on the benefits of reducing construction errors and improving clash detection and engineers value the improved models for simulation and analysis. Project that is mega and complex increases the chance for time and cost savings, due to the greater likelihood of reducing changes or errors. The awareness, benefits and takeup of BIM are visibly proven however, the implementation of BIM in Malaysian construction industry is yet at infancy stage. There are people-related issues, technology-related issues as well as process-related that hindering the level of uptake and speed of implementation of BIM in Malaysia. Amongst of these issues, in particular, legal and contractual aspects and

\footnotetext{
${ }^{*}$ Corresponding author: teoh.mjo@gmail.com
} 
the absence of appropriate protocols have been ranked as one of the highest or most critical barriers associated with the implementation of BIM.

As BIM requires a number of parties for example architects, engineers, contractors and associated supply chain members to collaborate the data into a $3 \mathrm{D}$ virtual model, it is argued brings up some legal issues such as ownership of the model, risk allocation of transferring data, copyright and insurance on the reliance of data, the interoperability between the parties of incorporation of BIM. These legal issues are vital in delivering BIM project, during the feasibility and planning stage of a construction project, procurement is the first decision to be made, but regardless any procurement methods, assessment of the contract provisions or clauses and the contents about BIM should be made aware to avoid conflicts and errors in the models/drawings. However, in Malaysia it can be said absent, that currently no specific contract form and legal framework on BIM can could possible contain, as expresses clauses, of all the complex body of law necessary to deal with BIM practice. A favourable contract or legal framework is fundamental at this stage.

The main aim of this study is to establish a viable framework that incorporates the standard form contract of the key clauses that narrate BIM processes in Malaysia, to serve as frame of reference for the industry professionals so it can be effectively realise during the procurement stage of BIM construction project. This study systematically reviews the specific legal and contract issues relating to BIM, BIM contract practices in some countries around the world, and key clauses specific to BIM. Limited by the progress of the study, this paper is not able to provide specific research findings, which are suggested as future tasks. The next section of this paper provides a systematic literature review, initial comparison framework and future direction of the study.

\section{Contract and Inclusion of BIM}

\subsection{Contractual Provisions Support BIM}

In most of the developed countries which have successfully implemented BIM practice in the construction industry, have enacted a BIM guideline to define the requirements, rules and regulation.

According to Greenwood et al. (2010) [4] and Brodie (2013) [5], in the United Kingdom (UK), the traditional approach is regularly implemented. The standard form contracts in UK mainly focus on the design copyright issue, a regulated permit is permitted to allow only such design in the construction of the model [5]. On the other hand, UK supports and benefits from Institution of Civil Engineer (ICE) standard form, NEC3, 2005, that encourages team spirit of "mutual trust and cooperation" [5].

Wheareas in the United States of America (USA), a group of the industry associations, ConsensesDOCS, published a BIM Addendum which its function is to create a BIM Execution Plan and the legal issues that are related to BIM could be resolved from there [4]. Two BIM specific contract initiatives have been developed in the USA. The AIA have published Document E202 - Building Information Modeling Protocol Exhibit (AIA, 2008), and ConsensusDOCS have published ConsensusDOCS 301 - Building Information Modeling Addendum (ConsensusDoCS, 2008)

In Singapore, has effectively adopted BIM technology. The Building Construction Authority (BCA) of Singapore commenced BIM Guide version 1.0 in the year of 2012. It was then revised in year 2013 as BIM Guide version 2.0 [14]. 
In spite of this, there is no recognised contract framework and a standard BIM guide in Malaysia today. A BIM Guide was issued in 2015 by the Department of the 1 Malaysia Housing Programme (PR1MA) Malaysia, which was specially designed for affordable housing projects in the PR1MA programme in year 2015. Then again, the PRIMA BIM Guide is not proposed to be taken as national BIM guideline [15]. Lack of established principle, uniform standard, and standardised practice., lead to confusion, inconsistencies, misunderstanding and gaps in BIM implementations.

\subsection{Legal and Contract Issues Relating to BIM}

Aside from organisation, people and technology issues, BIM raises a number of specific legal and contract issues. The contract issues arising from BIM, largely from the creation and the use of building information model, share risk and liability for those responsible for the model.

\subsubsection{Ownership of BIM Model}

The client, who is also the paymaster, wish to own the model after completion for facilities management purposes and so on [6]. Yet, the issue of ownership might be brought up when the data and information are contributed by the designers i.e. architects and engineers [7].

\subsubsection{Intellectual Property Rights}

BIM speed up the design phases of project, allowing for rapid virtual model prototyping. Those parties such as architects, structural engineers, mechanical and electrical (M\&E) engineers and so on, who supply data and information into the BIM model, might hope to protect their own copyright and intellectual property right [8]. Issue of plagiarism might be raised while the data is shared among the design teams during the design process of the model [9]. This is because each of the designers might have the opinion that the ideas or designs are originated by them.

\subsubsection{LOD of BIM model}

The design team members who are involved in generating the model, are responsible to ensure that the progress is in line with the Level of Development (LOD) of the BIM model. LOD (i.e. LOD $100,200,300,350,400 \& 500$ ) is a reference guideline to specify and articulate the level of clarity/details of the model content at different stages. It allows client or any users to understand the limitation of model and it information availability [10]. For example, at LOD 100 information related to the model element or building element (e.g. the size of wall, cost, volume and quantity etc.) can be derived of the model element itself. At LOD 200, the objects, assemblies and other generic systems are shown with approximate quantities, dimensions, shape orientation and location.

All project team members are obliged to perform "duty of care" in order to make certain that the model could be progressed accordingly throughout the period of design [11]. However, as the model develops, conflicts might arise between the parties. Client could increasingly demand for models with greater details and asking to be sent to the contractor in more accurate and have fabrication details. The main challenge is that, if there are no mechanisms to control and draw the line of LOD, it would create overwhelming and affects the professionals service agreements on project.

\subsubsection{Model Management and Record}


The potential problem associated with model management and data record is that, because multiple parties involve in providing and submitting information to the model, error and corruption of data could inadvertently input into the model. The potential for such magnified accountability must be acknowledged in the contract. Respective party must be assigned correctly the obligation to take care of the model. For instance, anyone especially the lead designer might be blamed for duty of care of the model when problem occurs [12]. Unfortunately, during the development of BIM, the parties involved are able to amend the data, it is challenging to find out the responsible party in this situation [13].

\subsubsection{Allocation of Risk}

According to Greenwood et al. (2010) [4], omission or insufficient information for the BIM models is mainly emphasised by the current legal state and all parties are obliged to ascertain that adequate information to be provided for their purpose. However, the probability of unwanted and incorrect information might be exchanged when BIM models collect or transfer information to all parties. The risk of erroneous information might also be transferred from one to another. Hence, this is a vital consideration for the existing standard form contract, to highlight in additional information as well. Also, there is another risk that design inconsistencies and clashes of the model might happen during the transfer of data, which also bring to additional work to resolve [10].

\subsubsection{Schedule of BIM Deliverables}

The schedule of BIM deliverables is required to ensure the competent development and progress of the model [10]. In the schedule, deadlines as well as cut-off date of the submission and approval of design information and other data should be well clarified, and complied by the project team members. Also, Mosey et al. (2016) [10], further explained that without clarification of the schedule, Lack of clarification of schedule could lead to misinterpretation and miscommunication among the parties, thus the deadlines need to be made clear at each stage.

\section{Review and Comparison Framework of Local Standard Forms}

In this study, two local standard forms of contract that are commonly used in the construction project in Malaysia that is PAM Contract 2006 and CIDB Standard Form of Contract for Building Works 2000 Edition, are reviewed and compared in the Table 1 below. By viewing the common standard forms used, provisions and clauses can be highlighted to suit BIM practice. Then, appropriate adjustment or inclusion of the clauses or the contract contents could then be made to become a fitting BIM procurement by reviewing and comparing those issues.

From the Table 1, based on thematic analysis findings, it can be observed that in the local standard forms, it is essential to add or enhance the clauses to relate the BIM issues such as the ownership of model and data, intellectual property rights, LOD of the BIM model, model management, allocation of risk, and schedule of BIM deliverables. As unclear standard is established, the higher the chance of conflicts to be occurred on site, which is opposed to the original objective of successful BIM practice. 
Table 1. Thematic analysis of comparison of Local Standard Forms

\begin{tabular}{|c|c|c|}
\hline $\begin{array}{l}\text { Legal Issues } \\
\text { related to BIM }\end{array}$ & PAM Contract 2006 & $\begin{array}{l}\text { CIDB Standard Form of Contract } \\
\text { for Building Works } 2000\end{array}$ \\
\hline $\begin{array}{l}\text { Ownership of } \\
\text { BIM Model }\end{array}$ & $\begin{array}{l}\text { Clause } 3.3 \text { Copies of Documents } \\
\text { The contract documents, drawings and } \\
\text { unpriced contract bills are clearly } \\
\text { stated to be provided by the Architect } \\
\text { or Quantity Surveyor to the Contractor } \\
\text { under this clause. However, there is no } \\
\text { clause that mention about the BIM } \\
\text { model. }\end{array}$ & $\begin{array}{l}\text { Clause } 4.2 \text { Custody of Contract } \\
\text { Documents } \\
\text { In this clause, it clearly states that } \\
\text { the contract documents shall remain } \\
\text { in the custody of the Employer. It } \\
\text { also does not mention about the } \\
\text { custody of the BIM model. }\end{array}$ \\
\hline $\begin{array}{l}\text { Intellectual } \\
\text { Property Rights }\end{array}$ & $\begin{array}{l}\text { Clause } 7.0 \text { Royalties and Intellectual } \\
\text { Property Rights } \\
\text { Under sub-clause } 7.1 \text { Indemnity to } \\
\text { Employer, any articles, processes, } \\
\text { inventions or drawings should be } \\
\text { included in the contract sum in order } \\
\text { to indemnify the employer because } \\
\text { this might prevent the Contractor from } \\
\text { infringing the intellectual property } \\
\text { rights. } \\
\text { Yet, this clause does not clearly state } \\
\text { that BIM model is the right of the } \\
\text { Employer or Contractor because the } \\
\text { designer or drafter of the model should } \\
\text { be the Contractor, but the Employer is } \\
\text { the paymaster. }\end{array}$ & $\begin{array}{l}\text { Clause 9.1(a) Patent Rights } \\
\text { The Contractor shall defend and } \\
\text { indemnify the Employer in the event } \\
\text { of infringement of any patent rights, } \\
\text { design trademarks or other protected } \\
\text { rights such as construction plants, } \\
\text { equipment, materials, goods and } \\
\text { design. } \\
\text { This clause mentions about design } \\
\text { but does not further clarify whether } \\
\text { it includes BIM model. }\end{array}$ \\
\hline $\begin{array}{l}\text { Level of } \\
\text { Development } \\
\text { (LOD) of BIM } \\
\text { model }\end{array}$ & $\begin{array}{l}\text { Clause } 6.5 \text { Work Not in accordance } \\
\text { with the Contract } \\
\text { This clause states that if the Architect } \\
\text { finds any work, materials, goods or } \\
\text { workmanship which is not in } \\
\text { accordance with the Contract, the } \\
\text { Contractor is responsible to take } \\
\text { necessary actions. } \\
\text { The clause does not explain that if the } \\
\text { LOD of BIM model is not in } \\
\text { accordance, whom shall the } \\
\text { responsible party. }\end{array}$ & $\begin{array}{l}\text { Clause } 7.1 \text { Contractor's General } \\
\text { Responsibilities } \\
\text { The Contractor is obliged with due } \\
\text { care and diligence, design, execute } \\
\text { and complete the works and remedy } \\
\text { defects in accordance with the } \\
\text { provisions of the contract. } \\
\text { Although this clause does mention } \\
\text { about responsibility of Contractor to } \\
\text { design, yet it does not make clear } \\
\text { that who shall be responsible for the } \\
\text { LOD of BIM mode. }\end{array}$ \\
\hline
\end{tabular}




\begin{tabular}{|c|c|c|}
\hline $\begin{array}{l}\text { Model } \\
\text { Management }\end{array}$ & $\begin{array}{l}\text { Clause } 3.4 \text { Further Drawings or } \\
\text { Details } \\
\text { The Architect is responsible to provide } \\
\text { the Contractor further drawings, } \\
\text { details, levels and any other } \\
\text { information in order to enable the } \\
\text { Contractor to complete the works } \\
\text { accordingly. } \\
\text { The clause does not amplify that who } \\
\text { shall be responsible to manage the } \\
\text { BIM model. }\end{array}$ & $\begin{array}{l}\text { Clause } 4.7 \text { Supplementary Drawings } \\
\text { and Instructions } \\
\text { The Superintending Officer is } \\
\text { responsible to issue the Contractor } \\
\text { supplementary or revised drawings, } \\
\text { specifications or instructions. } \\
\text { The clause does not state that who } \\
\text { shall be responsible to manage the } \\
\text { BIM model. }\end{array}$ \\
\hline $\begin{array}{l}\text { Allocation of } \\
\text { Risk }\end{array}$ & $\begin{array}{l}\text { Clause } 1.4 \text { Discrepancy or Divergence } \\
\text { between Documents } \\
\text { In this clause, the risk of any } \\
\text { discrepancies and divergence of the } \\
\text { contract documents and following } \\
\text { documents falls under the Contractor. } \\
\text { Any errors are found, the Contractor } \\
\text { must foresee it and rectify with the } \\
\text { Architect or Engineer. } \\
\text { The clause emphasises on the contract } \\
\text { documents but does not clarify that if } \\
\text { any extension of time due to the BIM } \\
\text { model, whose responsibility it is. }\end{array}$ & $\begin{array}{l}\text { Clause } 7.4 \text { Responsibility for } \\
\text { Identifying the Discrepancy } \\
\text { The Contractor should find any } \\
\text { ambiguity, discrepancy, conflict, } \\
\text { inconsistency, error or omission. The } \\
\text { Superintending Officer should then } \\
\text { explain and adjust the discrepancy. } \\
\text { The clause emphasises on the } \\
\text { contract documents but does not } \\
\text { clarify that if any extension of time } \\
\text { due to the BIM model, whose } \\
\text { responsibility it is. }\end{array}$ \\
\hline $\begin{array}{l}\text { Schedule of } \\
\text { BIM } \\
\text { Deliverables }\end{array}$ & $\begin{array}{l}\text { Clause } 3.5 \text { Works Programme } \\
\text { Under this clause, the Contractor is } \\
\text { liable to submit the works programme } \\
\text { to the Architect within a reasonable } \\
\text { timeframe. The works programme } \\
\text { functions as the sequence of the works } \\
\text { to be carried out. } \\
\text { However, the works programme does } \\
\text { not include schedule of BIM } \\
\text { deliverables to show the sequence and } \\
\text { deadlines to complete each stage of the } \\
\text { model. }\end{array}$ & $\begin{array}{l}\text { Clause } 5.1 \text { Submission of Works } \\
\text { Programme and Method Statement } \\
\text { The Contractor is responsible to } \\
\text { submit a works programme related } \\
\text { to the time for completion clearly } \\
\text { identifying the sequence, logic and } \\
\text { critical path. } \\
\text { However, the works programme } \\
\text { does not include schedule of BIM } \\
\text { deliverables to show the sequence } \\
\text { and deadlines to complete each stage } \\
\text { of the model. }\end{array}$ \\
\hline
\end{tabular}




\section{Conclusions and Future Work}

From literature review, it is appearing that legal and contract issues relating BIM are very crucial and need priority for research. This study addressed the following one overarching question that need future research: As BIM in Malaysia is at infancy stage, what are basic principles, clauses and provisions that are important to be included in the current standard forms of contract? To answer this question, qualitative study will be used. This research highlights comparison between the contract issues regarding BIM and key clauses of two common standard form of contract in Malaysia. From the thematic analysis (Stage 1) of research), there are thematic connections of these two facets, and the findings of the analysis can be used as initial frame of reference to improve or inclusion of new clauses in the current contracts. The next stage of research (Stage 2) is expert interviews, as this method could help deepen the understanding on, and validate the earlier findings.

\section{References}

1. McAdam, Brodie. "Building information modelling: the UK legal context." International Journal of Law in the Built Environment 2.3 246-259. (2010)

2. W. Paper, Legal Implications of Building Information Modeling. Sheet Metal and Air Conditioning Contractors National Association, Inc., 112, 1-9 (2008)

3. Buncio A D n.d. Lowering Costs with Building Information Modeling

4. A. A. Latiffi, J. Brahim, S. Mohd, S. F .Fathi, The Malaysian Government's Initiatives in using Building Information Modeling (BIM) in Construction Pojects. Sustainable Solutions in Structural Engineering and Construction, (CREAM), 767-772 (2014)

5. D. Greenwood, S .Lewis, S. Lockley Contractual Issues in the Total Use of Building Information Modelling. W113 - Special Track 18th CIB World Building Congress, 363371. (2010)

6. P. K. Yau, An Insight onto the Implementation of BIM in Malaysian Construction Industry - Issues and Challenges (Heriot-Watt University) (2015)

7. Hamil S, 2011 The Top 10 BIM Questions, Retrieved from: http://www.thenbs.com/topics/bim/articles/top10bimquestions.asp (Accessed May 2017)

8. S. Azhar, M. Khalfan, T. Maqsood, Building Information Modeling (BIM): Now and Beyond. Retrieved

from: http://epress.lib.uts.edu.au/journals/index.php/AJCEB/article/view/3032 (Accessed May 2017) (2012)

9. D. Larson, K. Golden, Entering the Brave New World: An Introduction to Contracting for BIM, William Mitchell Law Review, 34, 1, 75-108 (2008)

10. D. Bryde, M.Broquetas, J.Volm, The Project Benefits of Building Information Modelling (BIM). (Elsevier), pp. 971-980. (2013)

11. D. Mosey, D. Bahram R. Dartnell, C, Hallam, C. Howard, M. Assad, M. Winfield Enabling BIM through Procurement and Contracts. Retrieved from https://www.kcl.ac.uk/law/research/centres/construction/enabling-bim/ebimtpacform.aspx (Accessed June 2017) (2016)

12. M. Al-Shammari, An Appraisal of the Protocol: the Construction Industry Council (CIC) to facilitate the use of Building Information Modelling (BIM) on Projects. Proceedings of the 30th Annual ARCOM Conference. Portsmouth, UK. Association of Researchers in Construction Management, 623-632. (2014) 
13. E. Lip, Client Practice Note Building Information Modelling - Key Contractual Perspectives, Director and Head of KPK Contracts Support Group, 4-7 (2012)

14. Sieminski J 2007 Liability and BIM Best Practices. AIA Pittsburgh, 1-3

15. Reddotbim 2015 BIM Standards. Available from: http://www.reddotbim.com/standards (Accessed June 2017)

16. PR1MA BIM Guide 2015 Perbadanan PR1MA Malaysia

17. S.U.M Tobi, D. Amaratunga Social Enterprise Applications in an Urban FM Setting: Research Methodological Perspectives. Salford Postgraduate Annual Research Conference (SPARC 2009). Manchester, UK.: University of Salford (2009)

18. H.J. Adèr, G. J. Mellenbergh, D. J. Hand, Advising on Research Methods: A Consultant's Companion. Huizen, The Netherlands: Johannes van Kessel (2008)

19. B. Bhatta, Research Method in Remote Sensing. Springer Briefs in Earth Sciences (2013)

20. D. A. De Vaus, Administering Questionnaires, Surveys in Social Research,4 St Leonards: Allen \& Unwin, 106-125 (1995)

21. P. Oliver, V. Jupp, Purposive Sampling. The SAGE Dictionary of Social Research Methods. Sage, 244-245 (2006)

22. M. Crozier, J- C. Thoenig, The Regulation of Complex Organized Systems. 21, 4, pp. 547-570 (1976). 